\title{
Osteogenic Sarcoma: A 21st Century Review
}

\author{
STEPHEN OSASAN ${ }^{1,2}$, MINGYONG ZHANG $^{1}$, FAN SHEN ${ }^{2}$, PAULOSE J. PAUL ${ }^{3}$, \\ SUJATA PERSAD ${ }^{4}$ and CONSOLATO SERGI ${ }^{1,2,5}$ \\ ${ }^{1}$ Department of Orthopedics, TianYou Hospital, \\ Wuhan University of Science and Technology, Wuhan, Hubei, P.R. China; \\ Departments of ${ }^{2}$ Laboratory Medicine and Pathology, ${ }^{3}$ Orthopedics, and ${ }^{4}$ Pediatrics, \\ University of Alberta, Edmonton, AB, Canada; \\ ${ }^{5}$ Stollery Children's Hospital, University of Alberta Hospital, Edmonton, AB, Canada
}

\begin{abstract}
Compared to other bone tumors, bone osteogenic sarcoma (BOS) continues to confer a much grimmer prognosis as the survival benefit of traditional chemotherapy treatment regimens is still unsatisfactory. Chemotherapy was demonstrated to be effective in eradicating both primary tumor and pulmonary metastases in the last century, with effective agents used in various combination regimens having changed the survival rate from less than $10 \%$ to $75 \%$. The most common primary bone cancer, BOS is conventionally a primary intramedullary high-grade malignant tumor characterized by malignant cells forming immature bone or osteoid. BOS is a disease with diverse morphological presentations. The treatment of all morphological variants seem to have been the same for over 30 years. The introduction of antiproliferative agents such as insulin growth factor-binding protein 3 hold promise of a potentially veritable therapeutic target. In this review, we highlight recent data on osteosarcoma to consolidate a platform able to connect bench and bedside.
\end{abstract}

The modern-day approach to therapy depends on the vast knowledge of the etiopathogenesis of the disease in question. Thus, the remedy is designed to modulate a critical point in disease evolution with the ultimate goal of halting the entire process or decelerating its progression while allowing the

This article is freely accessible online.

Correspondence to: Consolato M. Sergi, MSc, MD, Ph.D., FRCPC, Professor of Pathology and Adj. Prof. of Pediatrics, University of Alberta, 8440112 St., Edmonton, T6G2B7, AB, Canada. Tel: +1 7804077951, e-mail: sergi@ualberta.ca

Key Words: Bone, osteosarcoma, pathology, growth factors, insulin growth factor binding protein-3, review. functional immunological mechanism of the body to continue. The quest for the understanding of the etiopathogenesis of diseases is the main preoccupation of medically oriented research laboratories and endeavors. The anecdotal observation of disease progression through the lens of morphological changes in organs has been challenged by the advent of the molecular basis of pathology (1). The genetic basis of such molecules further extends the understanding of the origin of the observed morphological changes. The above postulation is overly naive being based on the assumption that an understanding of the molecules involved in any particular disease process and the morphological changes can reveal the path to the full elucidation of the therapeutic options. The classical testament to this is the use of human epidermal growth factor receptor-2 antagonist (HER2) in the treatment of HER2positive breast cancer (2). Nevertheless, this postulate has been shown not to be as valid as it seems in many diseases such as in bone osteogenic sarcoma (BOS). In our opinion, the challenge may be a lack of proper definition of the pathology itself. A disease such as BOS with different histological variants (3), may be a constellation of various diseases captured under a single name based on mere morphological and anatomical similarities with limited actual molecular/genetic etiopathogenetic basis. This dilemma is accentuated by the limitation in the number of cases and their heterogeneity.

In this mini-review, we summarize the current thinking on the epidemiology, genetic basis, and the molecular pathways involved in the pathogenesis of BOS. We examined the therapeutic challenges and discuss on insulin growth factor binding protein 3 as a plausible therapeutic target.

\section{BOS a Disease of the Growing Youth}

BOS is a malignant tumor in which the neoplastic cells make mineralized bone or osteoid matrix. It is the most common 
primary tumor of bone tissue. It represents about $20 \%$ of all malignant primary bone tumors. It has a bimodal age distribution; however, the majority, about $75 \%$, occur in children and youths $(4,5)$. BOS is usually associated with exposure to suspected risk factors such as ionizing radiation and other related diseases such as Paget's disease and LiFraumeni syndrome among others (3). Physical agents such as radiation have been implicated in about $2 \%$ of BOS, and it is suggested not to play a significant role in the etiology of the disease in young patients. However, some chemicals such as beryllium oxide, asbestos, and chromium salts have been suggested to play a role in the etiology (6-8). The role of biological agents in the etiology of this disease remains controversial (6).

The disease usually occurs in the metaphyseal region of rapidly growing bones, especially those of the extremities. About $50 \%$ occur around the knee, consisting of the epiphyseal plates of the distal femur and the proximal tibia (3). It has also been reported in the patellar bone (9). The rapid growth spurt during puberty until young adulthood associated with exposure to predisposing factors may be responsible for the preponderance of the disease at this early age. This is corroborated by the findings of Gelberg et al., who noted a significantly positive association of tumor with height 1 year before diagnosis as compared with other factors such as weight or body mass index (10). Mirabello et al. noted that individuals with high birth-weight as well as taller than average individuals had increased risk of BOS, suggesting that rapid growth in the bone, especially in utero, during puberty and early adulthood, contributes significantly to the etiology of the tumor $(11,12)$. Furthermore. despite a male:female incidence ratio of $1.5: 1$, the disease is said to occur at an earlier age in females compared to males, believed to be due to an earlier growth spurt in females compared to males. All the preceding then suggests that abnormalities involving growth factors and cell-cycle regulation, as well as overall cellular proliferation, are responsible for the manifestation of this disease entity.

\section{The Question of the Cell of Origin, Subtypes and Heterogeneity of BOS}

All neoplastic diseases are known to develop from particular renegade cells which acquire unique capabilities represented in the morphological changes characterizing the disease process. BOS is said to arise from the medullary cavity of the metaphysis of growing long bones, and surfaces of bones, as well as extraskeletal locations. The characteristics of the parent cell have been postulated to determine the biological behavior of the tumor (3). The varying morphological manifestations seen in the different subtypes of the tumor may be indicative of the different cells of origin of the subtypes, or clonal expression of a mutation in the genome of the parent stem cell. Klein and Siegal elucidated the various morphology of the tumor (3). The subtypes demonstrate the enormous phenotypic diversity of the tumor in form and grade. The conventional type is itself divided into osteoblastic, fibroblastic, chondroblastic, epithelioid, giant cell-rich, small cell and telangiectatic subtypes, these divisions being entirely based on morphological manifestation (13). The biological and morphological resemblance of some of the subtypes with other pathological conditions makes the suspicion of different entities rife (14, 15). However, the morphological manifestation may not be reflective of the original cell with the mutagenic alteration that gave rise to the tumor (13). Furthermore, distinct genetic mutations delineating the individual subtypes have not been elucidated. The fact that the defining feature of BOS is the production of osteoid by the tumor cells gives the impression that the primary cell of origin is the osteoblast, a cell with mesenchymal germline origin. It is also a known fact that the tumor microenvironment contributes significantly to the diagnostic definition and tumor development in each of the subtypes (16). Thus, Mutsaers and Walkley raised important questions about the cell of origin based on the apparent heterogeneity of whether the disease arises from a single cell type or different cell types. They further queried if it follows the model of tumorigenesis (13). Nevertheless, the consensus now, based on numerous animal models, is that imperfections in the downstream mesenchymal stem cell differentiation, as well as inconsistencies in the course of the osteogenic development from the parent mesenchymal stem cell, due to modulation by various mutagenic alterations mainly involving tumour-suppressor genes P53 and retinoblastoma, are heavily implicated in the development of this tumor (17).

\section{Genetics of BOS}

The studies of the genetic modifications leading to BOS are limited mainly to the few cases available. However, some studies have identified some single nucleotide polymorphisms (SNPs) associated with the risk of development of BOS. Some of the SNPs are presumed to be related to regulatory elements $(18,19)$. The mechanism of genetic alterations in BOS includes classical point-mutations and aneuploidy. In addition to this, a new form of genetic modification called chromothripsis is also involved (18) Chromothripsis is a cellular crisis in which there are tens to hundreds of genomic rearrangements with chromosomes crisscrossing back and forth across particular regions, generating frequent oscillations between two copy number states in a phenomenon described as a cellular catastrophe $(20,21)$.

BOS is a tumor with extensive morphological heterogeneity. The underlying genetic alterations leading to the tumor are also believed to be highly heterogeneous, thus 


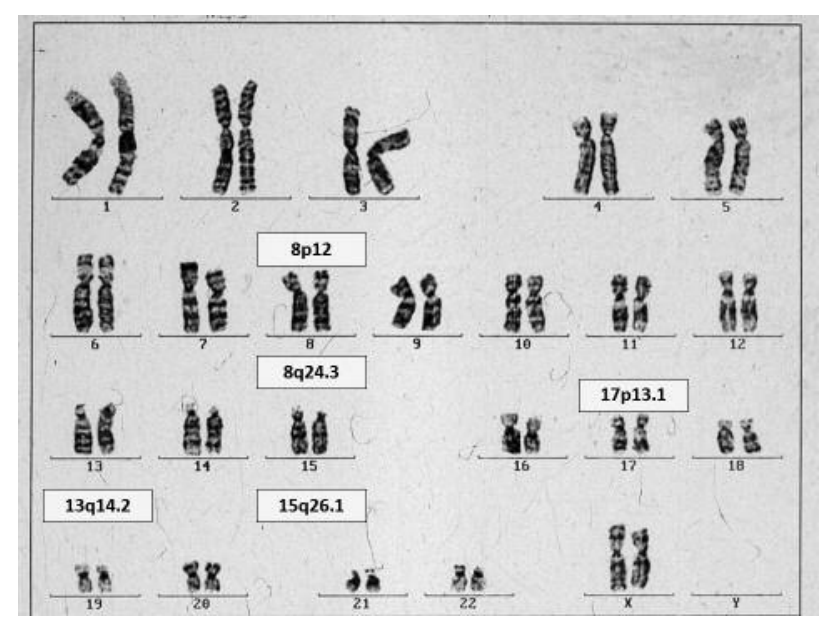

Figure 1. Osteosarcoma predisposing syndromes and their associated genes (the background of the figure is a normal female karyotype 46, XX). $17 p 13.1$ (TP53): Li-Fraumeni syndrome; $13 q 14.2$ (RB1): retinoblastoma; 8q24.3 (REQ4): Rothmund Thomson syndrome; $8 q 24.3$ (REQ4): Rapadilino syndrome; 8p12 (WRN): Werner syndrome; 15q26.1 (BLM): Bloom syndrome; multiple loci (RPS19, RPL5, RPL11, RPL35A RPS24, RPS17, RPS7, RPS10, RPS26): Diamond-Blackfan syndrome.

making the understanding of the molecular pathogenesis of the disease difficult. BOS is associated with chromosomal instability, which results in the malfunction of the cell-cycle checkpoints and DNA-repair mechanisms. The tumor is also associated with numerous aneuploidy multiple chromosomal losses or gains. It is said that chromosome 1 is the most gained, while chromosomes $9,10,13$, and 17 are the most lost. Furthermore, the deletions of portions of chromosomes $3,6,9,10,13,17$ and 18 with amplifications of parts of chromosomes $1,6,8$, and 17 are the major alterations noted in this tumor. These chromosomal changes are said to encode the tumor suppressors and oncogenes (18). BOS is associated with some genetic syndromes, that are listed in Figure 1 (22). In this figure, chromosomal loci and some components of the cell-cycle pathway and regulators in the development of this tumor are noted. Thus transcription factors such as $c-M Y C$ and $c-F O S$ play significant roles in the etiopathogenesis (18, $23)$. The other oncogenes associated with amplifications in BOS include CDC5L, MAPK7, MET, PIM1, PMP22, PRIM1, $R U N X 2$, and VEGFA (13).

In addition to the direct genetic alterations underlying the development of BOS, epigenetic changes have also been shown to play a role. Epigenetic modifications are those alterations in gene expression or phenotypic manifestation that are not due to direct changes in the DNA sequence. These involve processes such as DNA methylation, histone modification, nucleosome remodeling, and RNA-mediated events $(18,24,25)$. p16 is a tumor-suppressor protein that plays an important role in cell-cycle regulation by decelerating cells progression. In mammals, methylating the cytosine within a gene can change its expression. This usually occurs in cytosine-phosphate-guanine $(\mathrm{CpG})$ islands or DNA sites with $\geq 200 \mathrm{bp}, \mathrm{GC}$ rate $>50 \%$, and an observedto-expected $\mathrm{CpG}$ ratio $>60 \%$. Methylation of $\mathrm{CpG}$ islands in promoter regions is often associated with gene silencing. Aberrant methylation of DNA occurs in most cancers, leading to silencing of several tumor-suppressor genes. Hypermethylation has been cited to reduce gene expression at the p16INK4 locus (18). Lysine-specific demethylase 1 (LSD1), a histone demethylase, has been shown to be overexpressed in BOS and cell lines treated with the inhibitor of LSD1 show reduced cell growth $(18,26)$. Demethylation of the promoter regions of TSSC3, a proapoptotic gene, resulted in overexpression of the gene thereby suppressing the growth of BOS cell lines (27). Mu et al. reported that demethylation of tumor-suppressor genes in BOS may reduce the metastatic capability of the tumor $(28,29)$. Some microRNAs (miRNAs) are also suggested to be markers of prognosis (30).

\section{Transcription Factors in BOS}

Transcription factors facilitate the process of transcribing information from the DNA to single-stranded RNA by binding to promoter sequences on the gene. This process is carefully monitored in cells. The regulatory mechanism is, however, deranged in BOS cells. $c-F O S$ and $c$-JUN proto-oncogenes, and their proteins FOS and JUN, which are components of the activator protein 1 complex, are significantly upregulated in BOS. This protein complex is a transcription factor that regulates cell proliferation, differentiation, and bone metabolism. The protein complex has also been implicated in the propensity of these tumors for invasion and metastasis $(6$, 31, 32). Intranuclear transcription factor MYC, which promotes cells growth and proliferation, is also overexpressed in BOS, and it is associated with resistance to conventional chemotherapy $(23,33,34)$. It was, recently, reported that the antihelmintic drug niclosamide has anticancer potential in humans: it inhibits cell migration and wound closure and induces apoptosis and inhibits cell-cycle progression in BOS cells. Niclosamide is said to significantly inhibit the transcription factors E2F1, AP1, and c-MYC-responsive reporters, and it mildly inhibits the HIF1 $\alpha$, TCF/LEF, CREB, NFKB, SMAD/TGF $\beta$, and RBPJ/NOTCH pathway reporters (35). This further underscores the significant role of transcription factors in the pathogenesis of BOS.

\section{Growth Factors in BOS}

Growth factors such as IGF, connective tissue growth factor (CTGF) and TGF lead to accelerated proliferation of cells. The receptors for these growth factors are also overexpressed 
and activated in BOS. Moreover, the signals responsible for the downstream phenotypic manifestations of these receptors are said to be accentuated in BOS (23).

Bianchi et al. showed by immunohistochemical studies that BOS expresses growth factors such as NGF, TrKA, NT3, TrKC and VEGF in the cytoplasm of neoplastic cells and strongly expresses NT4 in the nuclear compartment. BDNF and TrKB showed strong expression predominantly in the extracellular matrix. They also found that TGF $\beta$ was strongly expressed in the extracellular matrix and vascular endothelium where it induced tumor growth through its receptor ALK5 and downstream activation of the transcription factor c-MYC $(36,37)$. BOS cells are said to induce endothelial cell proliferation thereby promoting neoangiogenesis (38). There is also the suggestion that HER2 might play a role in BOS pathogenesis and may be a therapeutic target based on the success recorded in breast cancer (39). Furthermore, IGFBP3 attenuated TGF $\beta 1$ activation of ERK1/2 and AKT in MG-63 cells and inhibited TGF $\beta 1$-induced cell-cycle progression and proliferation by mediating a signal cross-talk between TGF- $\beta$ and IGF signaling pathways in MG-63 BOS cells $(40,41)$. This is suggestive of a role for IGFBP3 as a potential therapeutic target for BOS.

\section{Role of Autophagy in BOS}

Autophagy is the process by which cells recycle cytoplasm and dispose of excess or defective organelles. This process is usually found in a state of inadequate nutrient supply to the cell from the extracellular environment. In the process of autophagy, internal proteins and some organelles are degraded and reused in the production of new cellular elements. The component to be cannibalized is enclosed by a doublemembrane structure known as the autophagosome which will fuse with the lysosome for the eventual enzymatic degradation of the besmirched organelle or cellular component (42). Autophagy can be both beneficial or detrimental to the neoplastic cell: it may act as a tumor suppressor, by being involved in type II programed cell death in cancer cells, and can limit cell size or may remove damaged organelles that could generate free radicals and increase mutations. On the other hand, it may allow survival of cancer cells within the nutrient-poor environment of a tumor, prevent cell death, and may protect against some cancer treatments (43).

Autophagy has been shown to play a role in the outcome of BOS. It has been demonstrated to confer radioresistance to BOS cells due to hypoxia induction (44). Prevention of autophagy has been shown to enhance the sensitivity of BOS cell lines to cannabinoid receptor agonist through the induction of apoptosis (45). It has also been shown to enhance type 2 programmed cell death in BOS following induction by some agents $(46,47)$.

\section{A Role for Apoptosis}

Healthy tissue integrity is maintained by a careful balance between cell growth and anti-proliferation through apoptosis, which is a form of programmed cell death. Therefore, inhibition of apoptosis and unregulated growth and development of mesenchymal tissue during bone development in children and young adults, as well as mutagenic induction of the bone tissues in some adults, are probably the primary etiological backgrounds for BOS. A therapeutic agent that can induce apoptosis and attenuate the activities of growth signals in the developing bones may be the key to the cure of this disease (46). The resistance of BOS to conventional therapy can be attributed to antiapoptotic factors in the tumor (47). Lin et al. found that inhibitory targeting of PDCD4 a pro-apoptotic tumor suppressor by miR-202 transfection of BOS cell lines significantly promoted chemotherapy resistance, while inhibition of miR-202 increased apoptosis, consequently enhancing drug sensitivity (48). Furthermore, it is pertinent to note that both mitochondrial and non-mitochondrial pathways of apoptotic induction have been shown to reduce the proliferative potential of BOS cell lines, in both the primary and the metastatic state (49-52). The apoptotic pathway, therefore, may hold the secret to adequately combating this disease and indeed other cancer types.

\section{The Challenges of Treatment}

The ultimate goal of any therapeutic effort is to return the patient to as near normal a life as possible. Patients undergoing treatment for BOS have had to come to terms with the significant modification of their social life (53). These alterations are the consequences of the available therapeutic options for the disease. In the addition to the desire to preserve the lives of patients, there is also need to develop therapeutic options that will reduce or eliminate the social and psychological burden imposed by the disease. The current therapy of BOS is a success story of the early 1970s. Before this time, the mainstay of the treatment of BOS was amputation. However, with the discovery of combination chemotherapy in addition to surgery, the outcome of localized tumor improved significantly. The survival rate increased from less than $20 \%$ to over $70 \%$. Patients were also able to have limb-sparing surgeries compared to outright amputation of the past $(54,55)$.

Nevertheless, the principal basis for the dismal morbidity and mortality of BOS is metastasis which has been reported to occur in over $80 \%$ of patients despite chemotherapy and surgical resection of the primary tumor. The main site of metastatic deposits of the tumor are the lungs. Tumour metastasis is primarily responsible for the stagnation in the development of new therapeutic targets for BOS in over 30 
years (56). The mainstay of the chemotherapeutic strategy of treating the disease has been the various preoperative and postoperative combination protocols of methotrexate, doxorubicin, cisplatin, cyclophosphamide, and ifosfamide. The advancements in the surgical therapies have been focused on total removal of the neoplastic tissue both at the primary site and metastatic locations while preserving the uninvolved tissue; this has reduced the propensity for amputation (57).

Radiotherapy has had little effect on the outcome of patients with BOS, the tumor has been labeled radioresistant. Some authors have attributed hypoxic changes as the main reason for resistance of BOS to radiotherapy (44). Nevertheless, the combination of radiation and chemotherapy has been shown to have considerable therapeutic effect in some patients (58).

The main pursuit of a new therapeutic target is the development of a 'magic molecule' that can inhibit the growth of tumor cells at the primary site and the distant metastatic site. The ideal molecule must be able to annihilate the neoplastic cell without collateral damage to the adjoining normal uninvolved tissue. There have been numerous attempts at identifying that novel therapeutic target. Nevertheless, the lack of full elucidation of the exact pathogenetic pathways in the etiology of the disease remains the Achilles tendon of identification of active therapeutic targets.

\section{IGFBP3: An Antiproliferative Agent}

IGFBP3 is a member of a six-membered protein family (IGFBP1 to IGFBP6) with multifunctional abilities. They have highly conserved structures and bind the factors IGF1 and IGF2 with high affinity. The IGFBP3 gene encodes this protein on human chromosome 7; it has four protein-coding exons with a fifth exon in the 3 ' untranslated region (59). IGFBP3 is the most abundant of the IGFBPs and is principally known for the transportation and stabilization of IGF in the circulation. IGFBPs also control the cellular activities of IGF thereby regulating the mitogenic activity of IGF in the extracellular environment. IGFBP3 is also known to exert cellular functions independent of IGF pathways (60). Several studies have elucidated the role IGF-independent actions of IGFBP3 (antiproliferative and proapoptotic properties) in many human diseases such as cancer and diabetes. Some of the studies highlighted the interaction of IGFBP3 with some protein pathways involved in cell-cycle control and apoptosis.

The IGFBP pathway has been shown to promote the proliferation and survival of BOS and other tumors, such as breast and prostate cancer $(61,62)$. Increased expression of IGFBP3 has been shown to contribute significantly to p53dependent apoptosis (63). p53 initiates the IGFBP3 antiproliferative activities in response to DNA-damage stimuli, such as ionizing radiation. It has also been shown that IGFBP3 mediates antiproliferative activities independently of p53. $\beta$ Importin has been reported to be necessary for the nuclear transportation of IGFBP3 (64). Nevertheless, the plasma membrane is suspected to be a significant barrier in the transportation from the extracellular compartment. A nuclear retinoid $\mathrm{X}$ receptor $\alpha$ has been shown to be necessary for IGFBP3 induced apoptosis, and RXR ligands were additive with IGFBP3 in inducing apoptosis (65).

Some studies have suggested that there are specific cellsurface receptors for IGFBP3 (66). Nevertheless, the only receptor that has demonstrated receptor ligand activity with IGFBP is the type 2 TGF $\beta$ receptor with subsequent SMAD signal transduction pathway.

\section{IGFBP3 and Bone}

IGF increases bone formation by regulating the proliferation, differentiation, and apoptosis of osteoblasts by binding IGF receptor type I. The IGFBPs regulate the IGFs by preventing their binding to the receptor and by controlling the amount of IGFs in the circulation that is available to local tissues (67). IGFBP3 is expressed in human osteoblasts. There is an inhibition of IGF receptor type I action and bone resorption, which may be a result of IGF receptor type I inhibition due to over sequestration by the excess IGFBP3 (68).

The work of Ressler et al. revealed the localization of IGFBP3 in the cytoplasm of BOS cells compared to its nuclear localization in osteocytes of healthy bone (69). Micutcova et al. by visual observation, using both confocal and electron microscopy, also noted accumulation of IGFBP3 vesicles in the cytoplasm, with few vesicles within the nucleus, despite confirming successful delivery of the vesicles into the nucleoplasm. They observed that although there was transportation of the protein into the nucleus, it seemed to be a rapidly degraded within the nucleus, thus suggesting ubiquitin/proteasome-dependent proteolysis (70). Santer et al. demonstrated that ubiquitin/proteasomedependent proteolysis directly regulates nuclear IGFBP3. They observed that IGFBP3 degradation depended on an active ubiquitin-E1 ligase. They reported that specific $26 \mathrm{~S}$ proteasome inhibitor efficiently stabilized nuclear IGFBP3, and the metabolic half-life of nuclear IGFBP3 was sharply reduced relative to cytoplasmic IGFBP3. They further noted that nuclear IGFBP3 was maintained through mutation of two COOH-terminal lysine residues. They, therefore, suggested that if IGFBP3 is expressed in the nucleus, apoptotic cell death will ensue (71). This may suggest a defect in one of the nuclear proteins involved in IGFBP3 activities within the nucleus. A study of the reason for the increase of ubiquitin/proteasome-dependent proteolysis in BOS as compared to normal osteocytes will be necessary to 
unravel the cause of the rapid degradation of IGFBP3 in the nucleus. Exogenous IGFBP3 has been noted to inhibit the growth of Ewing sarcoma cells significantly both in monolayer and anchorage-independent conditions; it diminishes cell motility, and inhibits the metastatic potential of sarcoma cells through an IGF-dependent pathway (72). This is suggestive that intranuclear IGFBP3 may be an active therapeutic target lacking in the therapy of BOS

\section{Conclusion}

The past four decades have seen a depressing stagnation in the effort at treating BOS. This is a malignant tumor of the bone with poor outcome, especially with metastasis. The diverse morphological presentation of the disease gives an impression of different entities with a common nomenclature. The pathogenetic pathway has been related to abnormalities in cellcycle control, along with other genetic and epigenetic abnormalities. Some molecular abnormalities are also associated with the disease. They all have a common denominator of encouraging cellular proliferation and inhibiting cell death. IGFBP3, which is related to increased apoptosis, is noticed to be lacking in the nucleus of malignant cells while it is present in the healthy cells. Thus, this molecule may be a veritable therapeutic target in the treatment of this disease. The lack of knowledge of the pathogenesis of the disease is the main reason for the stagnation in therapeutic efforts. The few cases available for study may also contribute to ignorance of the disease. More collaborative efforts will be needed to explore this disease in greater detail.

\section{References}

1 Strasser BJ: Perspectives: Molecular medicine. Sickle cell anemia, a molecular disease. Science 286(5444): 1488-1490, 1999.

2 Shepard HM, Jin P, Slamon DJ, Pirot Z and Maneval DC: Herceptin. Handb Exp Pharmacol 181: 183-219, 2008.

3 Klein MJ and Siegal GP: Osteosarcoma: Anatomic and histologic variants. Am J Clin Pathol 125(4): 555-581, 2006.

4 Mirabello L, Troisi RJ and Savage SA: International osteosarcoma incidence patterns in children and adolescents, middle ages and elderly persons. Int J Cancer 125(1): 229-234, 2009.

5 Sergi C and Zwerschke W: Osteogenic sarcoma (osteosarcoma) in the elderly: Tumor delineation and predisposing conditions. Exp Gerontol 43(12): 1039-1043, 2008.

6 Broadhead ML, Clark JC, Myers DE, Dass CR and Choong PF: The molecular pathogenesis of osteosarcoma: A review. Sarcoma 2011: 959248, 2011.

7 Dutra FR and Largent EJ: Osteosarcoma induced by beryllium oxide. Am J Pathol 26(2): 197-209, 1950.

8 Rani AS and Kumar S: Transformation of non-tumorigenic osteoblast-like human osteosarcoma cells by hexavalent chromates: Alteration of morphology, induction of anchorageindependence and proteolytic function. Carcinogenesis 13(11): 2021-2027, 1992.
9 Aoki M, Nishio J, Iwasaki H, Masaki M, Kawakami Y, Nishino T, Ohjimi $H$, Tamura $K$, Nabeshima $K$ and Naito $M$ : Osteosarcoma of the patella mimicking giant cell tumor: Imaging features with histopathological correlation. Anticancer Res 34(5): 2541-2545, 2014.

10 Gelberg KH, Fitzgerald EF, Hwang S and Dubrow R: Growth and development and other risk factors for osteosarcoma in children and young adults. Int J Epidemiol 26(2): 272-278, 1997.

11 Mirabello L, Pfeiffer R, Murphy G, Daw NC, Patino-Garcia A, Troisi RJ, Hoover RN, Douglass C, Schuz J, Craft AW and Savage SA: Height at diagnosis and birth-weight as risk factors for osteosarcoma. Cancer Causes Control 22(6): 899-908, 2011.

12 Longhi A, Pasini A, Cicognani A, Baronio F, Pellacani A, Baldini N and Bacci G: Height as a risk factor for osteosarcoma. J Pediatr Hematol Oncol 27(6): 314-318, 2005.

13 Mutsaers AJ and Walkley CR: Cells of origin in osteosarcoma: Mesenchymal stem cells or osteoblast committed cells? Bone 62: 56-63, 2014.

14 Machado I, Lopez Guerrero JA, Navarro S, Mayordomo E, Scotlandi K, Picci P and Llombart-Bosch A: Galectin-1 (GAL1) expression is a useful tool to differentiate between small cell osteosarcoma and ewing sarcoma. Virchows Arch 462(6): 665$671,2013$.

15 Lee AF, Hayes MM, Lebrun D, Espinosa I, Nielsen GP, Rosenberg AE and Lee CH: FLI-1 distinguishes ewing sarcoma from small cell osteosarcoma and mesenchymal chondro-sarcoma. Appl Immunohistochem Mol Morphol 19(3): 233-238, 2011.

16 Alfranca A, Martinez-Cruzado L, Tornin J, Abarrategi A, Amaral T, de Alava E, Menendez P, Garcia-Castro J and Rodriguez R: Bone microenvironment signals in osteosarcoma development. Cell Mol Life Sci 72(16): 3097-3113, 2015.

17 Miller CW, Aslo A, Won A, Tan M, Lampkin B and Koeffler HP: Alterations of the $p 53, R B$ and $M D M 2$ genes in osteosarcoma. J Cancer Res Clin Oncol 122(9): 559-565, 1996.

18 Morrow JJ and Khanna C: Osteosarcoma genetics and epigenetics: Emerging biology and candidate therapies. Crit Rev Oncog 20(3-4): 173-197, 2015.

19 Savage SA, Mirabello L, Wang Z, Gastier-Foster JM, Gorlick R, Khanna C, Flanagan AM, Tirabosco R, Andrulis IL, Wunder JS, Gokgoz N, Patino-Garcia A, Sierrasesumaga L, Lecanda F, Kurucu N, Ilhan IE, Sari N, Serra M, Hattinger C, Picci P, Spector LG, Barkauskas DA, Marina N, de Toledo SR, Petrilli AS, Amary MF, Halai D, Thomas DM, Douglass C, Meltzer PS, Jacobs K, Chung CC, Berndt SI, Purdue MP, Caporaso NE, Tucker M, Rothman N, Landi MT, Silverman DT, Kraft P, Hunter DJ, Malats N, Kogevinas M, Wacholder S, Troisi R, Helman L, Fraumeni JF, Jr., Yeager M, Hoover RN and Chanock SJ: Genome-wide association study identifies two susceptibility loci for osteosarcoma. Nat Genet 45(7): 799-803, 2013.

20 Stephens PJ, Greenman CD, Fu B, Yang F, Bignell GR, Mudie LJ, Pleasance ED, Lau KW, Beare D, Stebbings LA, McLaren S, Lin ML, McBride DJ, Varela I, Nik-Zainal S, Leroy C, Jia M, Menzies A, Butler AP, Teague JW, Quail MA, Burton J, Swerdlow H, Carter NP, Morsberger LA, Iacobuzio-Donahue C, Follows GA, Green AR, Flanagan AM, Stratton MR, Futreal PA and Campbell PJ: Massive genomic rearrangement acquired in a single catastrophic event during cancer development. Cell 144(1): 27-40, 2011.

21 Maher CA and Wilson RK: Chromothripsis and human disease: Piecing together the shattering process. Cell 148(1-2): 29-32, 2012. 
22 Calvert GT, Randall RL, Jones KB, Cannon-Albright L, Lessnick $S$ and Schiffman JD: At-risk populations for osteosarcoma: The syndromes and beyond. Sarcoma 2012: 152382, 2012

23 Gamberi G, Benassi MS, Bohling T, Ragazzini P, Molendini L, Sollazzo MR, Pompetti F, Merli M, Magagnoli G, Balladelli A and Picci P: c-MYC and c-FOS in human osteosarcoma: Prognostic value of mRNA and protein expression. Oncology 55(6): 556-563, 1998.

$24 \mathrm{Li} \mathrm{B}$ and $\mathrm{Ye} \mathrm{Z}$ : Epigenetic alterations in osteosarcoma: Promising targets. Mol Biol Rep 41(5): 3303-3315, 2014.

25 Cui J, Wang W, Li Z, Zhang Z, Wu B and Zeng L: Epigenetic changes in osteosarcoma. Bull Cancer 98(7): E62-68, 2011.

26 Bennani-Baiti IM, Machado I, Llombart-Bosch A and Kovar H: Lysine-specific demethylase 1 (LSD1/KDM1A/AOF2/BHC110) is expressed and is an epigenetic drug target in chondrosarcoma, Ewing's sarcoma, osteosarcoma, and rhabdomyosarcoma. Hum Pathol 43(8): 1300-1307, 2012.

27 Li Y, Huang Y, Lv Y, Meng G and Guo QN: Epigenetic regulation of the pro-apoptosis gene TSSC3 in human osteosarcoma cells. Biomed Pharmacother 68(1): 45-50, 2014.

$28 \mathrm{Mu}$ X, Sultankulov B, Agarwal R, Mahjoub A, Schott T, Greco N, Huard J and Weiss K: Chick embryo extract demethylates tumor-suppressor genes in osteosarcoma cells. Clin Orthop Relat Res 472(3): 865-873, 2014.

29 Zhou C, Tan W, Lv H, Gao F and Sun J: Hypoxia-inducible microrna-488 regulates apoptosis by targeting BIM in osteosarcoma. Cell Oncol doi 10.1007/s13402-016-0288-2, 2016.

30 Dong J, Liu Y, Liao W, Liu R, Shi P and Wang L: miRNA-223 is a potential diagnostic and prognostic marker for osteosarcoma. J Bone Oncol 5(2): 74-79, 2016.

31 Wu JX, Carpenter PM, Gresens C, Keh R, Niman H, Morris JW and Mercola D: The proto-oncogene $c$-FOS is over-expressed in the majority of human osteosarcomas. Oncogene 5(7): 989-1000, 1990.

32 Franchi A, Calzolari A and Zampi G: Immunohistochemical detection of c-FOS and c-JUN expression in osseous and cartilaginous tumours of the skeleton. Virchows Arch 432(6): 515-519, 1998.

33 Shimizu T, Ishikawa T, Sugihara E, Kuninaka S, Miyamoto T, Mabuchi Y, Matsuzaki Y, Tsunoda T, Miya F, Morioka H, Nakayama R, Kobayashi E, Toyama Y, Kawai A, Ichikawa H, Hasegawa T, Okada S, Ito T, Ikeda Y, Suda T and Saya H: Cmyc overexpression with loss of INK4A/ARF transforms bone marrow stromal cells into osteosarcoma accompanied by loss of adipogenesis. Oncogene 29(42): 5687-5699, 2010.

34 Scionti I, Michelacci F, Pasello M, Hattinger CM, Alberghini M, Manara MC, Bacci G, Ferrari S, Scotlandi K, Picci P and Serra M: Clinical impact of the methotrexate resistanceassociated genes $c-M Y C$ and dihydrofolate reductase $(D H F R)$ in high-grade osteosarcoma. Ann Oncol 19(8): 1500-1508, 2008.

35 Liao Z, Nan G, Yan Z, Zeng L, Deng Y, Ye J, Zhang Z, Qiao M, Li R, Denduluri S, Wang J, Wei Q, Geng N, Zhao L, Lu S, Wang X, Zhou G, Luu HH, Haydon RC, He TC and Wang Z: The anthelmintic drug niclosamide inhibits the proliferative activity of human osteosarcoma cells by targeting multiple signal pathways. Curr Cancer Drug Targets 15(8): 726-738, 2015.
36 Bianchi E, Artico M, Di Cristofano C, Leopizzi M, Taurone S, Pucci M, Gobbi P, Mignini F, Petrozza V, Pindinello I, Conconi MT and Della Rocca C: Growth factors, their receptor expression and markers for proliferation of endothelial and neoplastic cells in human osteosarcoma. Int $\mathrm{J}$ Immunopathol Pharmacol 26(3): 621-632, 2013.

37 Matsuyama S, Iwadate M, Kondo M, Saitoh M, Hanyu A, Shimizu K, Aburatani H, Mishima HK, Imamura T, Miyazono $\mathrm{K}$ and Miyazawa K: Sb-431542 and gleevec inhibit transforming growth factor-beta-induced proliferation of human osteosarcoma cells. Cancer Res 63(22): 7791-7798, 2003.

38 de Nigris F, Mancini FP, Schiano C, Infante T, Zullo A, Minucci PB, Al-Omran M, Giordano A and Napoli C: Osteosarcoma cells induce endothelial cell proliferation during neo-angiogenesis. J Cell Physiol 228(4): 846-852, 2013.

39 Gill J, Geller D and Gorlick R: HER-2 involvement in osteosarcoma. Adv Exp Med Biol 804: 161-177, 2014.

40 O'Rear L, Longobardi L, Torello M, Law BK, Moses HL, Chiarelli $\mathrm{F}$ and Spagnoli A: Signaling cross-talk between IGFbinding protein-3 and transforming growth factor-(beta) in mesenchymal chondroprogenitor cell growth. J Mol Endocrinol 34(3): 723-737, 2005.

41 Schedlich LJ, Yenson VM and Baxter RC: Tgf-beta-induced expression of igfbp-3 regulates IGF1R signaling in human osteosarcoma cells. Mol Cell Endocrinol 377(1-2): 56-64, 2013.

42 Monastyrska I and Klionsky DJ: Autophagy in organelle homeostasis: Peroxisome turnover. Mol Aspects Med 27(5-6): 483-494, 2006.

43 Shintani T and Klionsky DJ: Autophagy in health and disease: A double-edged sword. Science 306(5698): 990-995, 2004.

44 Feng H, Wang J, Chen W, Shan B, Guo Y, Xu J, Wang L, Guo $\mathrm{P}$ and Zhang $\mathrm{Y}$ : Hypoxia-induced autophagy as an additional mechanism in human osteosarcoma radioresistance. J Bone Oncol 5(2): 67-73, 2016.

45 Zhang G, Bi H, Gao J, Lu X and Zheng Y: Inhibition of autophagy and enhancement of endoplasmic reticulum stress increase sensitivity of osteosarcoma SAOS-2 cells to cannabinoid receptor agonist WIN55,212-2. Cell Biochem Funct 34(5): 351-358, 2016.

46 Zhao J, Zhang ZR, Zhao N, Ma BA and Fan QY: Vegf silencing inhibits human osteosarcoma angiogenesis and promotes cell apoptosis via PI3K/AKT signaling pathway. Cell Biochem Biophys 73(2): 519-525, 2015.

47 Wang $\mathrm{Y}$ and Teng JS: Increased multi-drug resistance and reduced apoptosis in osteosarcoma side population cells are crucial factors for tumor recurrence. Exp Ther Med 12(1): 81$86,2016$.

48 Lin Z, Song D, Wei H, Yang X, Liu T, Yan W and Xiao J: TGFbeta1-induced mir-202 mediates drug resistance by inhibiting apoptosis in human osteosarcoma. J Cancer Res Clin Oncol 142(1): 239-246, 2016.

49 Liang CZ, Zhang JK, Shi Z, Liu B, Shen CQ and Tao HM: Matrine induces caspase-dependent apoptosis in human osteosarcoma cells in vitro and in vivo through the upregulation of BAX and FAS/FASL and downregulation of BCL-2. Cancer Chemother Pharmacol 69(2): 317-331, 2012.

50 Yu X, Zhou X, Fu C, Wang Q, Nie T, Zou F, Guo R, Liu H, Zhang B and Dai M: Celastrol induces apoptosis of human osteosarcoma cells via the mitochondrial apoptotic pathway. Oncol Rep 34(3): 1129-1136, 2015. 
51 Huang G, Nishimoto $\mathrm{K}$, Yang $\mathrm{Y}$ and Kleinerman ES Participation of the fas/fasl signaling pathway and the lung microenvironment in the development of osteosarcoma lung metastases. Adv Exp Med Biol 804: 203-217, 2014.

52 Wu XY, Hao CP, Ling M, Guo CH and Ma W: Hypoxia-induced apoptosis is blocked by adrenomedullin via up-regulation of BCL-2 in human osteosarcoma cells. Oncol Rep 34(2): 787-794, 2015.

53 Fauske L, Bondevik H, Bruland OS and Ozakinci G: Negative and positive consequences of cancer treatment experienced by long-term osteosarcoma survivors: A qualitative study. Anticancer Res 35(11): 6081-6090, 2015.

54 Jaffe N: Osteosarcoma: Review of the past, impact on the future. The american experience. Cancer Treat Res 152: 239-262, 2009.

55 Jaffe N: Historical perspective on the introduction and use of chemotherapy for the treatment of osteosarcoma. Adv Exp Med Biol 804: 1-30, 2014.

56 Khanna C, Fan TM, Gorlick R, Helman LJ, Kleinerman ES, Adamson PC, Houghton PJ, Tap WD, Welch DR, Steeg PS, Merlino G, Sorensen PH, Meltzer P, Kirsch DG, Janeway KA, Weigel B, Randall L, Withrow SJ, Paoloni M, Kaplan R, Teicher BA, Seibel NL, Smith M, Uren A, Patel SR, Trent J, Savage SA, Mirabello L, Reinke D, Barkaukas DA, Krailo M and Bernstein M: Toward a drug development path that targets metastatic progression in osteosarcoma. Clin Cancer Res 20(16): 42004209, 2014.

57 Chen Y, Yu XC, Xu SF, Xu M and Song RX: Impacts of tumor location, nature and bone destruction of extremity osteosarcoma on selection of limb salvage operative procedure. Orthop Surg 8(2): 139-149, 2016.

58 Luetke A, Meyers PA, Lewis I and Juergens H: Osteosarcoma treatment - where do we stand? A state of the art review. Cancer Treat Rev 40(4): 523-532, 2014.

59 Cubbage ML, Suwanichkul A and Powell DR: Insulin-like growth factor binding protein-3. Organization of the human chromosomal gene and demonstration of promoter activity. J Biol Chem 265(21): 12642-12649, 1990.

60 Baxter RC: Signalling pathways involved in antiproliferative effects of IGFBP-3: A review. Mol Pathol 54(3): 145-148, 2001.

61 Bhattacharyya N, Pechhold K, Shahjee H, Zappala G, Elbi C, Raaka B, Wiench M, Hong J and Rechler MM: Nonsecreted insulin-like growth factor binding protein-3 (IGFBP-3) can induce apoptosis in human prostate cancer cells by igfindependent mechanisms without being concentrated in the nucleus. J Biol Chem 281(34): 24588-24601, 2006.

62 Leibowitz BJ, Agostini-Dreyer A, Jetzt AE, Krumm CS and Cohick WS: Igf binding protein-3 mediates stress-induced apoptosis in non-transformed mammary epithelial cells. J Cell Physiol 228(4): 734-742, 2013.
63 Rajah R, Valentinis B and Cohen P: Insulin-like growth factor (igf)-binding protein-3 induces apoptosis and mediates the effects of transforming growth factor-beta1 on programmed cell death through a p53- and igf-independent mechanism. J Biol Chem 272(18): 12181-12188, 1997.

64 Schedlich LJ, Le Page SL, Firth SM, Briggs LJ, Jans DA and Baxter RC: Nuclear import of insulin-like growth factor-binding protein-3 and -5 is mediated by the importin beta subunit. J Biol Chem 275(31): 23462-23470, 2000.

65 Baxter RC: Nuclear actions of insulin-like growth factor binding protein-3. Gene 569(1): 7-13, 2015.

66 Oh Y, Muller HL, Pham H and Rosenfeld RG: Demonstration of receptors for insulin-like growth factor binding protein-3 on hs578t human breast cancer cells. J Biol Chem 268(35): 2604526048, 1993.

67 Govoni KE, Baylink DJ and Mohan S: The multi-functional role of insulin-like growth factor binding proteins in bone. Pediatr Nephrol 20(3): 261-268, 2005.

68 Silha JV, Mishra S, Rosen CJ, Beamer WG, Turner RT, Powell DR and Murphy LJ: Perturbations in bone formation and resorption in insulin-like growth factor binding protein-3 transgenic mice. J Bone Miner Res 18(10): 1834-1841, 2003.

69 Ressler S, Radhi J, Aigner T, Loo C, Zwerschke W and Sergi C: Insulin-like growth factor-binding protein-3 in osteosarcomas and normal bone tissues. Anticancer Res 29(7): 2579-2587, 2009.

70 Micutkova L, Hermann M, Offterdinger M, Hess MW, Matscheski A, Pircher H, Muck C, Ebner HL, Laich A, Ferrando-May E, Zwerschke W, Huber LA and Jansen-Durr P: Analysis of the cellular uptake and nuclear delivery of insulinlike growth factor binding protein-3 in human osteosarcoma cells. Int J Cancer 130(7): 1544-1557, 2012.

71 Santer FR, Bacher N, Moser B, Morandell D, Ressler S, Firth SM, Spoden GA, Sergi C, Baxter RC, Jansen-Durr P and Zwerschke W: Nuclear insulin-like growth factor binding protein-3 induces apoptosis and is targeted to ubiquitin/ proteasome-dependent proteolysis. Cancer Res 66(6): 30243033, 2006.

72 Benini S, Zuntini M, Manara MC, Cohen P, Nicoletti G, Nanni $\mathrm{P}$, Oh Y, Picci P and Scotlandi K: Insulin-like growth factor binding protein 3 as an anticancer molecule in Ewing's sarcoma. Int J Cancer 119(5): 1039-1046, 2006. 